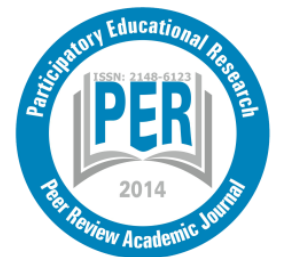

Participatory Educational Research (PER)

Vol. 6(2), pp. 206-220, December, 2019

Available online at http://www.perjournal.com

ISSN: 2148-6123

http://dx.doi.org/10.17275/per.19.22.6.2

\title{
Enhancing Elementary Pupils' Conceptual Understanding on Matter through Sci-vestigative Pedagogical Strategy (SPS)
}

\author{
Genalin A. Macanas \\ Faculty, Schools Division of Zambales, Department of Education, Philippines
}

Danilo V. Rogayan, Jr. "

Faculty, College of Education, Arts \& Sciences, President Ramon Magsaysay State

University, Philippines

Article history

Received:

01.11.2019

Received in revised form: 29.11.2019

Accepted:

01.12 .2019

Key words:

Action research, inquiry-based

learning strategy, science

teaching, Sci-vestigative

Pedagogical Strategy (SPS)
Teaching Science in a digital society where 21 st century skills are being harnessed is a perennial challenge. This is for the reason that teachers, specifically in the elementary level, are relentlessly modifying and innovating teaching strategies to improve science education. This action research study sought to explore the effects of Sci-vestigative Pedagogical Strategy (SPS) on the conceptual understanding on Matter of Grade 6 Science pupils. The study involved 29 pupils in the control group and 30 pupils in the experimental group in a public elementary school in the Division of Zambales for the School Year 2018-2019. Pre-test and post-test were administered before and after the application of the intervention to measure its effects on the conceptual understanding on matter of the pupils. The study found out that there was a significant difference in the conceptual understanding of the pupils in the experimental and control group. However, the use of SPS yielded a higher gain score compared to the gain score in the use of traditional method of instruction (TMI). The pupils' written works and performance tasks scores have also improved with the use of the SPS. The study recommends that Science teachers may use SPS to improve pupils' conceptual understanding including their concepts and content knowledge; depth within topics; and transfer and connections and to develop their higher order thinking and inquiry skills. School administrators may consider conducting training and workshops for Science teachers to reacquaint them of the basic rudiments of the Sci-vestigative Pedagogical Strategy which is based on inquiry-based learning. Students may be given varied roles in the agham (science) inquiry tasks so that they can better work as a group. A parallel study may be conducted by other teacher-researchers to validate the effects of the intervention in enhancing pupils' conceptual understanding in other topics. 


\section{Introduction}

The 21st century educational landscape demands more innovative and more engaging teaching strategies that would enhance learning, arouse learners' interest and facilitate better education for the Generation Z students (Rogayan \& Bautista, 2019; Rogayan, 2019). Science and technology (S\&T) are essential to the day-to-day life of humans and have an indispensable role in the development of products and innovations to make life better and to sustain basic necessities of life (Abdullaha \& Osman, 2010). S\&T can be a tool for creativity in different aspects (Sokol, Oget, Sonntag \& Khomenko, 2008) including science education. Hence, science teachers must make sure that the pedagogical strategies being employed in the classroom are responsive, research-based and relevant (Rogayan \& Dollete, 2019).

Through the advent of technology, science has become a very powerful tool in analyzing, exploring and discovering new concepts and ideas relevant in today's generation. Maxwell, Lambeth and Cox (2015) stressed that educators and science learning enthusiasts have recognized the importance of enhancing teaching methodologies used for science instruction in schools towards improving student achievement. Several researchers in science education are concerned by the lack of depth of conceptual understanding in science that students have exhibited for the past decades (Ganeb \& Morales, 2018; Ruiz-Gallardo, \& Reavey, 2019).

Conceptual understanding is the process of grasping ideas in a transferrable way which can facilitate learners to apply what they learn in class across domains. It is considered as timely topic in the classroom today, as rote memorization and traditional methods of teaching are becoming considered insufficient for real-world learning and application (Omari \& Chen, 2016). New knowledge is obtained as students gather data, interpret data, and do problemsolving. Rote memorization of facts does not enhance problem solving skills, however, when students are given the opportunity to probe, rationalize, and create new knowledge, they are capable to integrate new knowledge into their understanding (Miller, McNeal \& Herbert, 2010). Miller et al. (2010) likewise affirm that inquiry-based learning, like the SPS, can help improve students' understanding of the physical world through knowledge creation.

In this action research project, the researchers customized an inquiry-based learning strategy which is dubbed as the Sci-vestigative Pedagogical Strategy (SPS). Sci-vestigative is a portmanteau of the words science and investigative which is based from the principles of inquiry science Varma, Volkmann, and Hanuscin (2009) perceived that science should be instructed and practiced through inquiry. Science activities should involve development of the different basic and integrated science process skills. Memorizing concepts will not increase science process skills of students, but the freedom to probe and investigate through inquirybased learning will.

The SPS, conceptualized by the researchers, involves a multitude of basic and integrated science process skills. In SPS, pupils are the center of the teaching-learning process wherein they work collaboratively in given set of inquiry tasks with a minimal supervision of the teacher. The SPS is an instructional strategy to promote meaningful science learning via greater student involvement. Since teachers are challenged to keep innovation alive in science teaching, the researchers gauged the effects of the developed learning strategy in improving the conceptual understanding of Grade 6 pupils specifically on matter. 


\section{Conceptual Framework}

With prior knowledge, students can create connections with their new knowledge. The Sci-vestigative Pedagogical Strategy (SPS) is a pedagogical tool that facilitates development of students' problem solving, creative thinking and critical thinking skills, which are essential in daily life (Maxwell, Lambeth \& Cox, 2015).

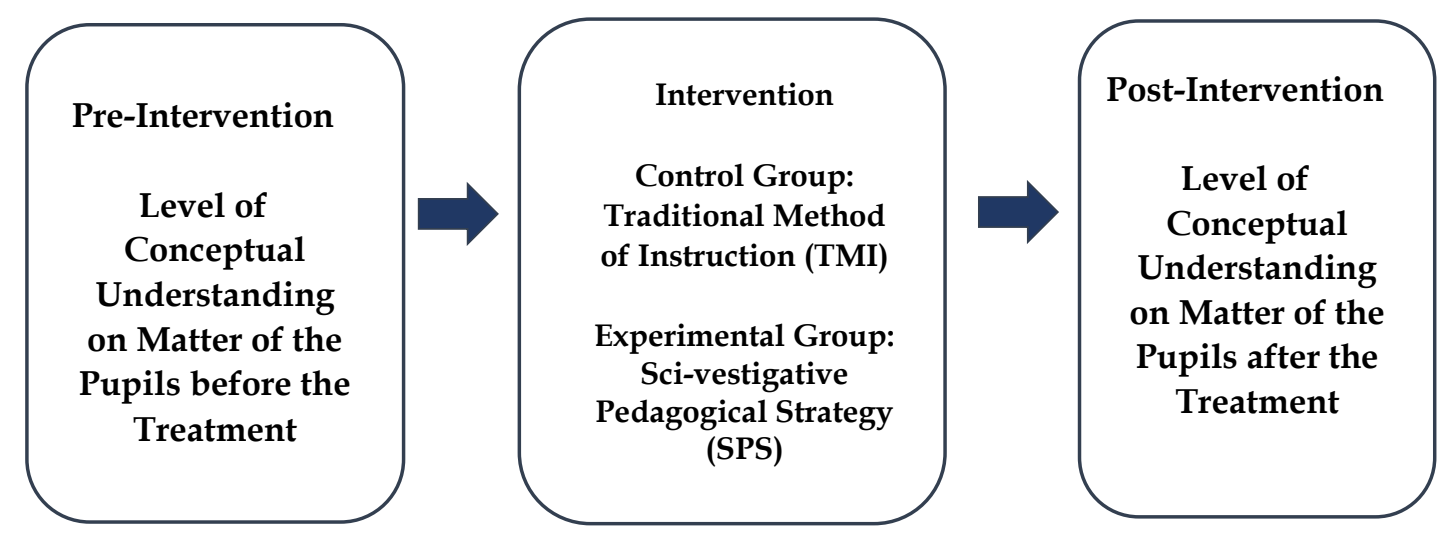

Figure 1. Paradigm of the Study

Figure 1 shows the paradigm of the study. The pre-intervention gauges the level of conceptual understanding on matter of the Science pupils before the treatment. The process includes two treatments, the traditional method of instruction (TMI) in the control group and the Scivestigative Pedagogical Strategy (SPS) in the experimental group. The output will be the level of conceptual understanding on matter of Grade 6 pupils of both in the control and experimental group.

\section{Purpose of the Study}

This research aimed to determine the effects of Sci-vestigative Pedagogical Strategy (SPS) in improving the conceptual understanding on matter of the Grade 6 pupils in a public elementary school in the Division of Zambales. Specifically, it aimed to answer the following research questions:

1. What is the level of conceptual understanding on matter of the Grade 6 pupils in the control and experimental group based on the pretest?

2. How is the conceptual understanding enhanced during the application of the intervention based on written works and performance task scores?

3. What is the level of conceptual understanding on matter of the Grade 6 pupils in the control and experimental group based on the post-test?

4. Is there a significant difference on the conceptual understanding on matter of the pupils in the control and experimental group before and after the treatment?

5. What are the insights of the teacher-researcher in the implementation of the Scivestigative Pedagogical Approach in Science class?

\section{Methodology}

\section{The Research Model}

This study is a two-group quasi-experimental action research. The control group was taught using the traditional method of instruction (TMI) while the experimental group was 
taught using the Sci-vestigative Pedagogical Strategy (SPS). It described the level of conceptual understanding on matter of the pupils before and after the application of the TMI and SPS.

\section{The Study Group}

A total of 59 Grade 6 pupils of a government-owned elementary school in the school year (SY) 2018-2019 served as the participants of the study, 29 pupils for the control group and 30 pupils for the experimental group.

\section{Data Collection Procedure}

Approval to the authorities and obtaining informed consent from parents of the participants were secured prior to the conduct of the study. The pre-test was conducted at the start of the lesson to measure the conceptual understanding on matter of the class before the application of the technique. On the other hand, post-test was administered toward the end of the study to determine how much the said technique helped in improving the level of conceptual understanding on matter. The Pre-Test and Post-Test are composed of 50 items.

Pre-Test was administered before the start of the unit to determine the weaknesses of the pupils on matter and its properties. The results of the pre-test likewise served as the basis of the grouping of the pupils for their aghamic group (learning team or grouping of the pupils) in the experimental group. Post-Test was administered to the pupils at the end of the unit to determine the improvement after exposure to SPS.

The Sci-vestigative Pedagogical Strategy (SPS) as an inquiry-based learning strategy is a pupilcentered and activity-based intervention. The steps of the developed instructional strategy were based on literatures on inquiry-based learning and laboratory-based instruction. The steps The following steps were customized by the teacher-implementer and were done in the experimental group.

1. Let's Engage. The teacher engaged her pupils through the use of various motivational activities such as using video clips, flat pictures, songs and thought-provoking question.

2. Know the Directions. Before the activity proper, the teacher had a pre-activity discussion wherein pupils listened to the directions of the activities to be done.

3. Do the Agham Inquiry Task (AIT). The different aghamic groups worked on their respective laboratory-based Agham (Filipino word for science) inquiry tasks through collaborating with their respective learning agham buddies. The agham inquiry tasks (AIT) are focused on the concept of matter, its properties and changes that materials undergo. The AIT is composed of the following parts:

a. Pre-lab Activity. The teacher asks questions about the laboratory safety precaution and the learner has to familiarize the materials to use. The teacher will also discuss the objectives and procedures of the activity. Then the pupils will proceed to their respective aghamic groups.

b. Lab Activity Proper. Actual conduct of the laboratory. The pupils were given the time to work with to their aghamic groups and discuss their work.

c. Post-Lab Discussion. Member of each aghamic groups answers all specific questions raised by the teacher.

4. Share the Results. Chosen presenters in each aghamic group presented their respective outputs. The teacher then critiqued and evaluated the presented inquiry tasks using rubrics.

5. Check the Conceptual Understanding. The pupils' conceptual understanding of the day is evaluated by means of check-up quizzes and other written works. 
With the use of SPS as a major strategy in teaching, the researcher used several materials in facilitating learning in a more efficient way. Such material includes laboratory apparatuses, photographic images and real objects. On the other hand, the traditional method of instruction (TMI) for the control group involved lecture-based instruction wherein teachers are the sole purveyors of knowledge. The TMI does not employ experiential learning of the pupils. It simply presents established facts or portraying a smooth path to knowledge. Conceptual understanding of the pupils is merely developed through a teacher-dominated instruction.

The SPS is a pupil-centered instructional strategy while TMI is a teacher-centered technique. In the SPS, experiential learning of pupils is accentuated compared to the TMI where teachers dominate the teaching-learning process. The pupils in the SPS are co-creators of conceptual understanding and knowledge but in TMI, teachers are the sole purveyors of knowledge and understanding. Table 1 shows the procedure for implementing the intervention.

Table 1. Procedure for Implementing Experimental and Control Classes

\begin{tabular}{|c|c|c|c|c|c|c|}
\hline \multicolumn{7}{|c|}{ Meeting } \\
\hline Weeks & 1 & 2 & 3 & 6 & 7 & 8 \\
\hline \multirow{2}{*}{ Class } & \multirow{2}{*}{$\mathrm{O}_{1}$} & \multicolumn{4}{|c|}{ Experimental (SPS) } & $\mathrm{O}_{2}$ \\
\hline & & \multicolumn{4}{|c|}{ Control (TMI) } & $\mathrm{O}_{2}$ \\
\hline
\end{tabular}

The intervention lasted for eight weeks. This quasi-experimental research was conducted from June 25 to August 13, 2018.

\section{Data Collection Tools}

To gather the data in determining the effects of SPS among Grade 6 pupils, several instruments were used by the researchers.

Pretest/ post-test. The 50-item test measured the level of conceptual understanding on matter of Grade 6 pupils. The test measured the level of conceptual understanding on matter of Grade 6 pupils. The topics covered in this study is the Properties of Matter during the first quarter of Grade 6 Science under the K to 12 curriculum. At the end of the unit, learners shall demonstrate understanding of different types of mixtures and their characteristics. Item analysis of the test was done to ensure its reliability and validity.

Written works. These instruments ensure that learners are able to express skills and concepts in written form. These include check-up quizzes about the topic which help strengthen test-taking skills among the learners.

Performance tasks. These allow learners to demonstrate what they know and are able to do in diverse ways. They may create or innovate products or do performance-based tasks. Performance-based tasks may include skills demonstration, laboratory work, and group presentations.

\section{Data Analysis}

To determine the effects of SPS, the data were analyzed using test of homogeneity (Levene's test), item analysis, frequency and percent distribution, weighted mean, standard 
deviation and t-test. The standards used in the score interpretations are based from the national standards prescribed by the Department of Education (DepEd) used in the Philippine context.

Table 2: Score Interpretation in Pretest and Post-test*

\begin{tabular}{lll}
\hline Scores & Abbreviation & Verbal Description (VD) \\
\hline $41-50$ & O & Outstanding \\
$31-40$ & VS & Very Satisfactory \\
$21-30$ & S & Satisfactory \\
$11-20$ & FS & Fairly Satisfactory \\
\hline $1-10$ & DNM & Did Not Meet Expectations \\
\hline
\end{tabular}

*Based from DepEd Order No. 8, s. 2015

Table 3: Performance Interpretation in Written Works and Performance Tasks*

\begin{tabular}{lll}
\hline Percent of Performance & Abbreviation & Verbal Description (VD) \\
\hline $96-100$ & M & Mastered \\
$86-95$ & CAM & Closely Approximating Mastery \\
$66-85$ & MTM & Moving Towards Mastery \\
$35-65$ & A & Average \\
$16-34$ & L & Low \\
$5-15$ & VL & Very Low \\
\hline $0-4$ & ANM & Absolutely No Mastery \\
\hline
\end{tabular}

*Based from DepEd National Achievement Test (NAT) Standards

\section{Results and Discussion}

\section{Pupils' Level of Conceptual Understanding on Matter before the Treatment}

The results of the pre-test determined the level of conceptual understanding of the pupils in the control and experimental group prior to the infusion of the SPS (Table 4).

Table 4. Level of Conceptual Understanding of Pupils before the Treatment

\begin{tabular}{lllll}
\hline \multirow{2}{*}{ Pre-Test Scores } & \multicolumn{2}{l}{ Control Group } & \multicolumn{2}{l}{ Experimental Group } \\
\cline { 2 - 5 } & Frequency & Percent & Frequency & Percent \\
\hline $21-30$ & 1 & 3.45 & 0 & 0.00 \\
$11-20$ & 20 & 68.97 & 21 & 70.00 \\
$1-10$ & 8 & 27.59 & 9 & 30.00 \\
Total & 29 & 100.0 & 30 & 100.0 \\
\multirow{2}{*}{ Average } & $\mathbf{1 3 . 4 8}$ (Fairly Satisfactory) & $\mathbf{1 2 . 3 3}$ (Fairly Satisfactory) \\
& SD =3.81 & & SD = 2.70 \\
\hline
\end{tabular}

Legend: 41-50 (Outstanding); 31-40 (Very Satisfactory); 21-30 (Satisfactory); 11-20 (Fairly Satisfactory); 1-10 (Did Not Meet Expectations)

The results of the pre-test of pupils in the control group showed that the group belonged to the Fairly Satisfactory level in terms of level of performance as revealed by the weighted mean of 13.48 ( $S D=3.81$ ). The test scores came majority from the bracket of 11 to 20 out of the 50-item Science test. Meanwhile, the experimental group yielded a weighted mean of $12.33(S D=2.70)$ in the pre-test which is likewise classified as Fairly Satisfactory. Majority of the pupils got scores within the bracket of 11 to 20 out of the 50-item test. 
Before the use of the intervention, the level of conceptual understanding on matter of the pupils is very low as revealed by the weighted mean of both groups. The pretest performance of the experimental group is lower than the performance of the control group. Several researchers (Buxton, Lee \& Santau, 2008; Furtado, 2010; Varma, et al., 2009) suggested that to achieve increased student participation, critical thinking skills, and achievement, students must be taught in an inductive process. To further analyze the score distribution of the pretest in the control and experimental group, histograms were presented (Figure 2).
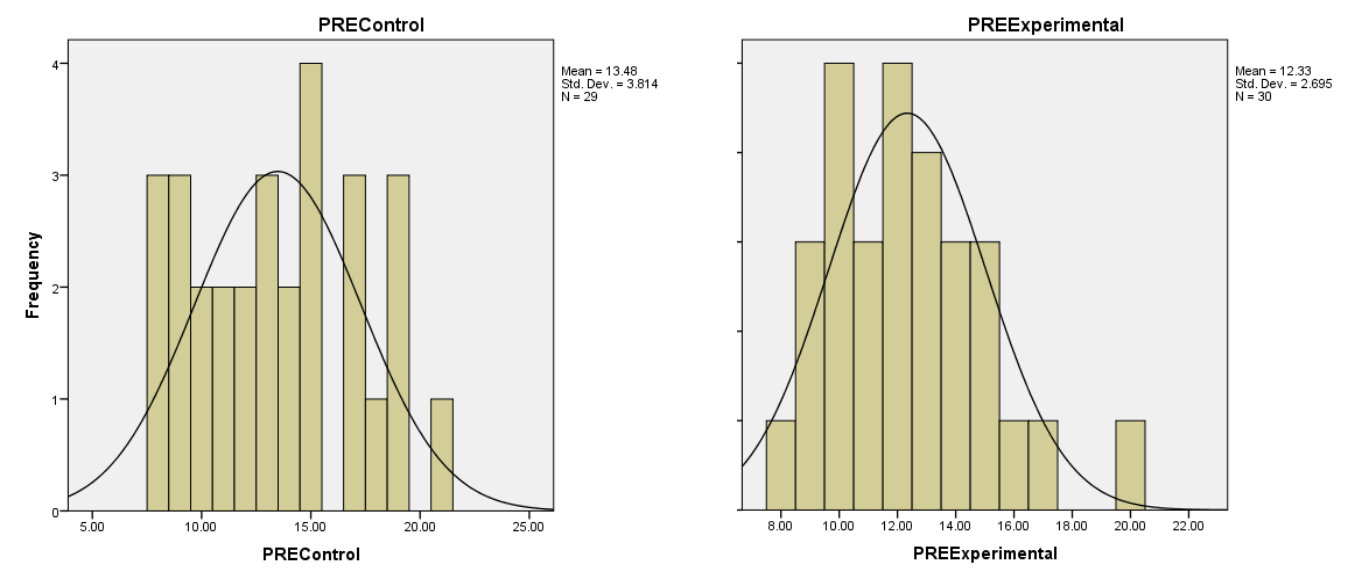

Figure 2. Score Distribution in Pretest in the Control and Experimental Group

The skewness coefficient of the control group is 0.193 while the experimental group has a skewness coefficient of 0.774 . Both of the values are positive which imply that the score distributions are positively skewed before the intervention. Most of the scores are low; hence, most of the pupils got scores below the mean value. To test if the two groups are homogenous, a Levene's test of homogeneity of variances was calculated based on the pretest results of the control and experimental group (Table 5).

Table 5. Levene's test table of homogeneity of variances

\begin{tabular}{llll}
\hline Levene Statistic & df1 & df2 & Sig. \\
\hline 5.160 & 1 & 57 & 0.207 \\
\hline
\end{tabular}

Significant $p<0.05 *$ *qual variances are assumed

The table shows that the Levene statistic is $F(1,57)=5.160, p=0.207$. The significant value of 0.207 is greater than 0.05 , therefore, it is not statistically significant. It indicates that the assumption of the homogeneity of variances was not violated. Therefore, the two groups are assumed as equal and so the study was carried out. The researchers also determined the level of proficiency of pupils in the different subskills of conceptual understanding of pupils (Table $6)$.

Before the treatment, the pupils' proficiency in the control group in terms of conceptual understanding is only $20.69 \%$ which means that only 6 out of 29 pupils can perform well in all the sub-skills of the conceptual understanding. The highest among the three sub-skills was on the Transfer and Connections with $24.14 \%$ class performance. On the other hand, a $16.67 \%$ class performance was recorded in the experimental group in terms of conceptual understanding. Still, the Transfer and Connections was the highest sub-skill performed with $20.00 \%$ class performance. 
Table 6. Pupils' Level of Proficiency in the Different Sub-skills of Conceptual Understanding prior the Treatment

\begin{tabular}{|c|c|c|c|c|}
\hline \multirow[b]{2}{*}{ Sub-skills } & \multicolumn{2}{|l|}{ Control Group } & \multicolumn{2}{|c|}{ Experimental Group } \\
\hline & $\begin{array}{l}\text { Number of } \\
\text { Pupils }\end{array}$ & Percent & $\begin{array}{l}\text { Number of } \\
\text { Pupils }\end{array}$ & Percent \\
\hline $\begin{array}{l}\text { Concepts and Content } \\
\text { Knowledge }\end{array}$ & 5 & 17.24 & 5 & 16.67 \\
\hline Depth within Topics & 6 & 20.69 & 5 & 16.67 \\
\hline $\begin{array}{ll}\text { Transfer } & \text { and } \\
\text { Connections } & \end{array}$ & 7 & 24.14 & 6 & 20.00 \\
\hline Total & 29 & 100.0 & 30 & 100.0 \\
\hline Weighted Mean & 6 & 20.69 & 5 & 16.67 \\
\hline
\end{tabular}

It can be implied that before the intervention, only few pupils can perform the different subskills of conceptual understanding. The pupils were facing difficulty in concepts and content knowledge, and depth within topics skills. Only few pupils have strong transfer and connections prior to the treatment in both control and experimental groups. Konicek-Moran and Keeley (2015) cited that when students have a developed conceptual understanding, they can think with it, utilize it in other disciplines, explain it in their own way, devise an analogy for it, or illustrate a mental or physical model of it. This simply means that the pupils have made the concept their own and that they understand it conceptually.

\section{Pupils' Level of Conceptual Understanding on Matter during the Treatment}

To monitor the progress of the students' conceptual understanding during the application of the SPS, written works and performance tasks scores were recorded. Table 7 shows the summary of scores in the three written works (WW).

Table 7. Pupils' Scores in the Written Works

\begin{tabular}{|c|c|c|c|c|c|c|c|c|}
\hline \multirow[b]{2}{*}{ Written Work } & \multicolumn{4}{|c|}{ Control Group } & \multicolumn{4}{|c|}{ Experimental Group } \\
\hline & $\mathbf{X}$ & SD & $\begin{array}{l}\% \text { of } \\
\text { Performance }\end{array}$ & VD & $\mathbf{X}$ & SD & $\begin{array}{l}\% \text { of } \\
\text { Performance }\end{array}$ & VD \\
\hline WW 1 (20 items) & 11.45 & 1.90 & 57.24 & A & 13.50 & 2.11 & 67.50 & MTM \\
\hline WW 2 (20 items) & 13.17 & 1.61 & 65.86 & MTM & 14.57 & 2.05 & 72.83 & MTM \\
\hline WW 3 (20 items) & 12.55 & 2.37 & 62.76 & A & 14.93 & 2.18 & 74.67 & MTM \\
\hline Overall & 37.17 & 4.59 & 61.95 & $\mathbf{A}$ & 43.00 & 4.98 & 71.67 & $\begin{array}{l}\text { MT } \\
\text { M }\end{array}$ \\
\hline
\end{tabular}

Legend: M-Mastered (96-100\%); CAM-Clearly Approximating Mastery (86-95\%); MTM-Moving Towards Mastery (66-85\%); A-Average (35-65\%); L-Low (16-34\%); VL-Very Low (5-15\%); Absolutely No Mastery (04\%); VD-Verbal Description

As shown in the table, the control group's weighted scores in the written works are in the Average Level during the application of the strategy as revealed by the $61.95 \%$ overall performance. Meanwhile, a higher written works mean scores were obtained in the experimental group yielding $71.67 \%$ class performance which belongs to the Moving towards Mastery level. The results suggest that the performance of the pupils in the experimental group is higher than the control group with the use of the pedagogical strategy. Table 8 shows the summary of scores in pupils' performance tasks. 
Table 8. Pupils' Scores in the Performance Tasks

\begin{tabular}{lllll|llll}
\hline \multirow{2}{*}{ Performance Task } & \multicolumn{3}{l}{ Control Group } & \multicolumn{5}{c}{ Experimental Group } \\
\cline { 2 - 9 } & Mean & SD & $\begin{array}{l}\text { \% of } \\
\text { Performance }\end{array}$ & VD & Mean & SD & $\begin{array}{l}\text { \% of } \\
\text { Performance }\end{array}$ & VD \\
\hline PT 1 (20 items) & 14.03 & 2.08 & 70.17 & MTM & 15.60 & 2.39 & 78.00 & MTM \\
PT 2 (25 items) & 19.38 & 1.57 & 77.52 & MTM & 18.57 & 2.56 & 74.28 & MTM \\
PT 3 (25 items) & 20.24 & 1.33 & 80.97 & MTM & 20.70 & 2.39 & 82.80 & MTM \\
Overall & $\mathbf{5 3 . 6 6}$ & $\mathbf{3 . 8 8}$ & $\mathbf{7 6 . 6 5}$ & MTM & $\mathbf{5 4 . 8 7}$ & $\mathbf{5 . 9 6}$ & $\mathbf{7 8 . 3 8}$ & MTM \\
\hline
\end{tabular}

Legend: M-Mastered (96-100\%); CAM-Clearly Approximating Mastery (86-95\%); MTM-Moving Towards Mastery (66-85\%); A-Average (35-65\%); L-Low (16-34\%); VL-Very Low (5-15\%); Absolutely No Mastery (0$4 \%)$

In terms of performance task, the control group obtained a $76.65 \%$ overall performance which is in the Moving towards Mastery level. Meanwhile, the experimental group yielded a $78.38 \%$ class performance which is likewise interpreted as Moving towards Mastery. It can be deduced that the experimental group yielded higher mean scores in performance task compared to the control group, suggesting the effectiveness of the Sci-vestigative Pedagogical Strategy (SPS).

The results are parallel with the study of Furtado (2010) that in implementing inquiry-based strategy like SPS, the teacher should give a complex real-world problem for pupils to work on. Furtado (2010) stressed that in the process of problem solving, pupils do not just memorize facts, but they also observe, ask questions, and solve, which makes them realize the importance of the facts.

\section{Pupils' Level of Conceptual Understanding on Matter after the Treatment}

To assess the effectiveness of the strategy used by the teacher-implementer, a post-test was administered after the application of the TMI and SPS (Table 9).

Table 9. Level of Conceptual Understanding of Pupils after the Treatment

\begin{tabular}{lllll}
\hline \multirow{2}{*}{ Post-Test Scores } & \multicolumn{2}{l}{ Control Group } & \multicolumn{2}{l}{ Experimental Group } \\
\cline { 2 - 5 } & Frequency & Percent & Frequency & Percent \\
\hline $41-50$ & 0 & 0.00 & 9 & 30.00 \\
$31-40$ & 19 & 65.52 & 17 & 56.67 \\
$21-30$ & 10 & 34.48 & 4 & 13.33 \\
Total & 29 & 100.0 & 30 & 100.0 \\
Average & $\mathbf{3 2 . 6 2}$ (Very Satisfactory) & $\mathbf{3 7 . 8 3}$ (Very Satisfactory) \\
& SD $\mathbf{5 . 6 6}$ & & $\mathbf{S D}=\mathbf{4 . 7 9}$ & \\
\hline
\end{tabular}

Legend: $41-50$ (Outstanding); $31-40$ (Very Satisfactory); 21-30 (Satisfactory); 11-20 (Fairly Satisfactory); 1-10 (Did Not Meet Expectations)

Post-test results showed that none of the class belonged to did not meet expectations level and fairly satisfactory level in the control and experimental group. The bulk of test scores in the post-test of the control group was in the bracket of 31 to 40 with 19 pupils $(65.52 \%)$. With the weighted mean of 32.62, the control group was classified in the Very Satisfactory level after the use of traditional method of instruction (TMI). Meanwhile, the bulk of test scores in the post-test of the experimental group was in the bracket of 31 to 40 with 17 pupils (56.67\%). Nine (9) pupils (30.00\%) belonged to Outstanding level after the use of Sci-vestigative Pedagogical Strategy (SPS). 
Learners' innate curiosity to probe and investigate must be developed well in a science learning space. Aydeniz, Cihak, Graham, and Retinger (2012) emphasized that in order to enhance the quality of learning and ensure that each learner achieves in science, inquiry skills must be developed over rote learning of facts. They stated that using inquiry-based strategy, like the SPS, can make pupils understand the concepts better, apply these concepts to real-life scenarios, and use scientific argumentation to measurement. The teacher-implementer also determined the level of proficiency of pupils in the different subskills of conceptual understanding of pupils after the treatment.

Table 10. Pupils' Level of Proficiency in the Different Subskills of Conceptual Understanding after the Treatment

\begin{tabular}{lllll}
\hline \multirow{2}{*}{ Sub-skills } & \multicolumn{2}{l}{ Control Group } & \multicolumn{2}{l}{ Experimental Group } \\
\cline { 2 - 5 } & Number of Pupils & Percent & Number of Pupils & Percent \\
\hline Concepts and Content & 18 & 62.07 & 23 & 76.67 \\
Knowledge & & & & \\
Depth within Topics & 17 & 58.62 & 25 & 83.33 \\
Transfer and Connections & 21 & 72.41 & 27 & 90.00 \\
Total & 29 & 100.0 & 30 & 100.0 \\
Weighted Mean & $\mathbf{1 8}$ & $\mathbf{6 2 . 0 7}$ & $\mathbf{2 5}$ & $\mathbf{8 3 . 3 3}$ \\
\hline
\end{tabular}

After the treatment, the pupils' proficiency in the control group in terms of conceptual understanding is $62.078 \%$ which means that 18 out of 29 pupils can perform well in all the subskills of the conceptual understanding. The highest among the three sub-skills was on the Transfer and Connections sub-skill with 21 pupils (72.41\%). On the other hand, a class performance of $83.33 \%$ was recorded in the experimental group in terms of conceptual understanding. Transfer and Connections sub-skill was the highest sub-skill performed with 27 pupils or $90.00 \%$ class performance. It can be implied that after the intervention, majority of the pupils can perform the different sub-skills of conceptual understanding. The pupils have improved much in the Transfer and Connections sub-skill which is the central objective of Science to make learning relevant, meaningful and useful to life.

This claim is supported by the study of National Assessment of Educational Progress (2003) that pupils show conceptual understanding when they are able to identify and give examples of concepts; utilize and explain models, graphs and different representations of concepts; explain and use principles; comprehend and apply facts and definitions; compare and contrast related concepts and principles; and interpret and utilize the signs, symbols, and terms used to represent concepts. To further analyze the score distribution of the post-test in the control and experimental group, histograms were presented (Figure 3).
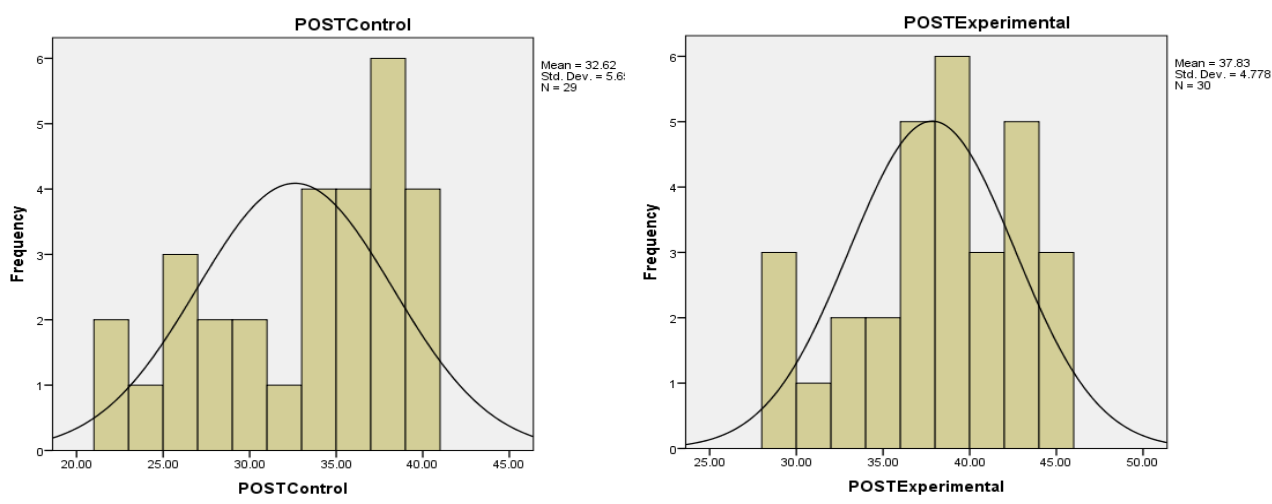

Figure 3. Score Distribution in Post-test in the Control and Experimental Group 
The skewness coefficient of the control group is -0.576 while the experimental group has a skewness coefficient of -0.460 . Both of the values are negative which imply that the score distributions are negatively skewed after the intervention. Most of the scores are high; hence, most of the pupils performed well in the post-test. To easily compare the mean scores of the two groups in the pretest and post-test, a graph is presented below (Figure 4).

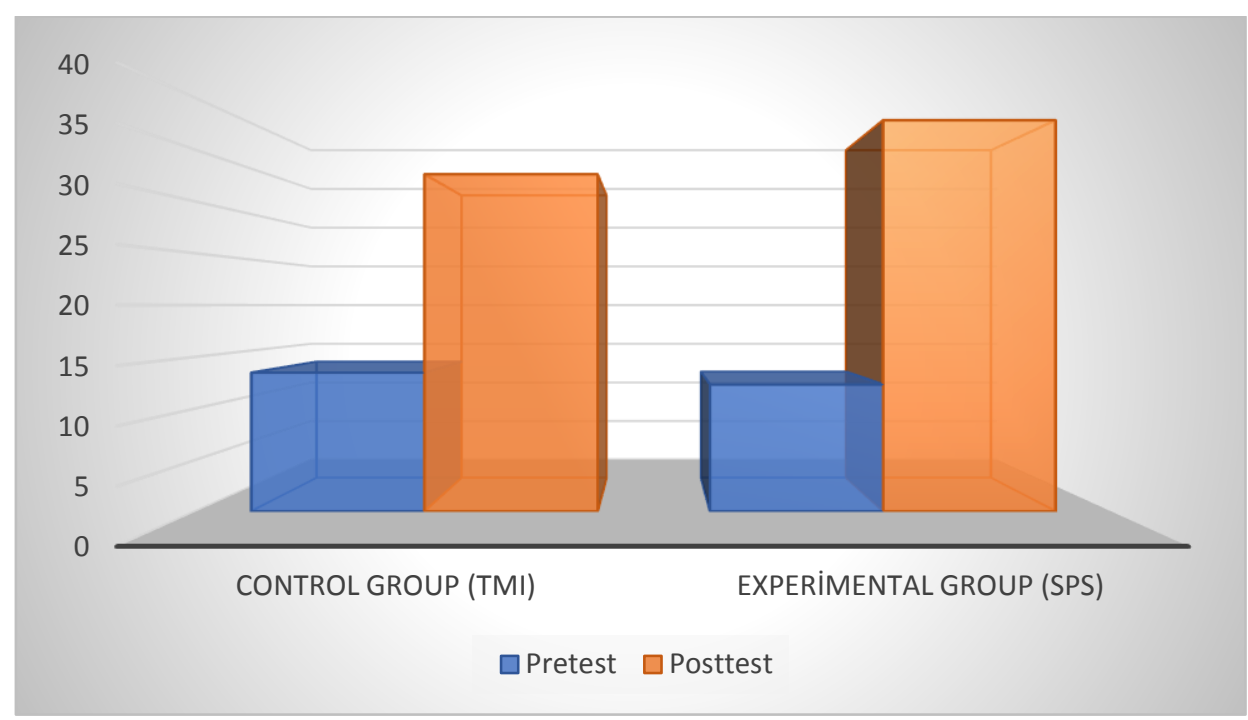

Figure 4. Mean Comparison of Pretest and Post-test Scores in Two Groups

It can be seen from the graph that prior to the intervention, both groups have low conceptual understanding on matter. After the treatment, the control group using the TMI has improved the pupils' conceptual understanding while the experimental group using the SPS likewise improved pupils' conceptual understanding. However, it can be noted that higher post-test mean score in the experimental group $(\mathrm{M}=37.83)$ was obtained compared to the control group $(\mathrm{M}=32.62)$. Hmelo-Silver, Duncan, and Chinn (2007) state that inquiry-based learning is a process of obtaining content and discipline-specific reasoning proficiency and practices by collaboratively participating in the investigation.

\section{Difference in the Conceptual Understanding on Matter prior and after the Treatment}

To measure the significant difference after the use of the teaching strategy, the mean difference between the scores in pretest and post-test in both the control and experimental groups is presented in Table 11.

Table 11. T-test of the Pretest and Post-test Mean Gain of the Control and Experimental Groups in the Science Test

\begin{tabular}{lllllll}
\hline Group & $\begin{array}{l}\text { Post-test } \\
\text { Mean }\end{array}$ & $\begin{array}{l}\text { Pretest } \\
\text { Mean }\end{array}$ & $\begin{array}{l}\text { Gain } \\
\text { Score }\end{array}$ & $\boldsymbol{t}$-value & $\boldsymbol{p}$-value & Remarks \\
\hline Control & 32.62 & 13.48 & 19.14 & 28.296 & 0.0000 & Significant \\
Experimental & 37.83 & 12.33 & 25.50 & 42.480 & 0.0000 & Significant \\
\hline
\end{tabular}

$p<.05$ *equal variances assumed

The Science 6 class in the control group obtained a mean gain score of 19.14 from the post-test score of 32.62 and pretest score of 13.48. Using the t-test for paired samples, a t-value of 28.296 was computed and the p-value was 0.0000 implying that there is a significant difference in the 
level of conceptual understanding on matter of pupils after the traditional method of instruction (TMI). Although, there is a significant difference in the control group, the experimental group yielded a higher gain score of 25.50 from the post-test score of 37.83 and pretest score of 12.33. Using the t-test for paired samples, a t-value of 42.480 was computed and the p-value was 0.0000 implying that there is a significant difference in the level of conceptual understanding on matter of pupils after the use of Sci-vestigative Pedagogical Strategy (SPS). The findings of the study also confirmed the conclusions of several researchers. Kazempour (2009) states that science educators need to assist and facilitate learning where pupils need to assume an active role in constructing their own learning experience. Evaluation was also critical in gauging prior understanding and checking pupil conceptual knowledge throughout the learning experience.

Watters and Ginns (2000) further described that inquiry-based strategy can provide teachers higher confidence in terms of science pedagogy. Pupils exposed in SPS showed a deeper understanding of science content. Kazempour (2009) recommends that inquiry-based practices can encourage a deeper understanding of science about the real world than traditional mode of teaching. This further implies that SPS is a pupil-centered methodology where the learning environment uses active learning in a small-group setting. Furthermore, Thompson (2017) stressed that the experiential learning that pupils acquire through creative thinking contributes to their functional literacy and readiness for the 21 st century and in the new industrial era. They reiterated that educators have always considered creative and critical thinking and inquiry as an essential component of any curriculum.

\section{Insights and Reflections of the Teacher-Implementer in the Application of the Sci- vestigative Pedagogical Approach in Science class}

Based on the journal entries of the teacher-implementer in the application of the Scivestigative Pedagogical Strategy (SPS), that intervention used in the experimental group was said to be an effective strategy in enhancing pupils' conceptual understanding on matter. It was also found out that the pupils in the control group are passive in learning compared to the pupils in the experimental group using the SPS who are more active, engaging, with higher interpersonal interactions and tend to be more inquisitive and more cooperative in their respective aghamic groups.

Moreover, higher order thinking skills and critical thinking skills are more developed among the pupils in the experimental group compared to the control group which received the traditional way of teaching. The teacher-implementer likewise realized that critical scrutiny of the inquiry tasks using rubrics is also important to ensure the successful attainment of the learning outcomes. The teacher-implementer likewise realized that using an innovative teaching strategy in Science will make the teaching-learning process more engaging and more inquiry-based. The challenge for educators of science is to continually think of innovative ways to make science more responsive and relevant (Tabiolo \& Rogayan, 2019).

For pupils to fully benefit from SPS, teachers must be retooled in the basic rudiments of the said strategy for them to be more confident in using this technique in their science classes. Kazempour (2009) stated professional development activities may improve teachers' technological pedagogical content knowledge. Hence, science educators must attend capacitybuilding activities to better understand the process of employing the instructional method in class and update their knowledge on learning content. In inquiry-based learning like the SPS, students develop initiative individually or collaboratively, disciplinary and multi-disciplinary expertise, innovative and creative skills, through research-based investigations of authentic 
questions interesting for the students (Chichekian, Savard, \& Shore, 2011).

\section{Conclusions and Recommendations}

The study found out that prior to the treatment, the Science 6 pupils in both the control and experimental groups are performing Fairly Satisfactory in terms of conceptual understanding. During the intervention, the conceptual understanding of the pupils in the experimental group has enhanced to moving towards mastery level in both written works and performance tasks. Meanwhile, the control group likewise improved their performance to average in their written works and to moving towards mastery in their performance task. The experimental group, however, obtained higher mean scores in written works and performance tasks compared to the control group. After the treatment, the pupils' conceptual understanding and sub-skills in the control and experimental group has improved to Very Satisfactory. Transfer and Connections sub-skill was the highest sub-skill performed by both groups. Further, there is a significant difference in the level of conceptual understanding of Science pupils in both the control and experimental group. However, a higher mean gain score was recorded in the experimental group which used the Sci-vestigative Pedagogical Strategy (SPS) compared to the control group using Traditional Method of Instruction (TMI) suggesting the effectiveness of SPS. The teacher-implementer realized that the use of SPS as an inquiry-based learning strategy enhances pupils' inquiry skills, critical thinking, higher order thinking and most importantly, their conceptual understanding.

The study hereby recommends that Science teachers may use SPS to improve pupils' conceptual understanding including their Concepts and Content Knowledge, Depth within Topics and Transfer and Connections as well as develop their higher order thinking and inquiry skills. School administrators may consider conducting training and workshops for Science teachers to reacquaint them of the basic rudiments of the Sci-vestigative Pedagogical Strategy which is based on inquiry-based learning. Pupils may be given varied roles in the agham inquiry tasks so that they can better work as a group. Also, Science teachers may innovate the inquiry tasks to be performed by the pupils to make it more engaging and more inquiry-based in nature. Monitoring report may be generated in every agham inquiry tasks so that behavioral changes among the aghamic groups will be recorded in a detailed manner. Since the strategy was only applied in small population, a parallel study may be conducted for a higher number of pupils to validate the effects of the intervention in enhancing pupils' conceptual understanding not only on matter but also in other Science topics.

\section{Acknowledgments}

The authors would like to extend their profoundest gratitude to the Schools Division of Zambales, Department of Education, for the approval to conduct the study, to the school principal of the respondent school, and to the Grade 6 parents and pupils for the active participation and willingness to take part in this action research project. The authors are also indebted to the College of Education, Arts \& Sciences of the President Ramon Magsaysay State University - San Marcelino for the support and assistance.

\section{References}

Abdullah, M., \& Osman, K. (2010). 21st century inventive thinking skills among primary students in Malaysia and Brunei. Procedia Social and Behavioral Science, 9, 1646 1651. https://doi.org/10.1016/j.sbspro.2010.12.380 
Aydeniz, M., Cihak, D., Graham, S., \& Retinger, L. (2012). Using inquiry-based instruction for teaching science to students with learning disabilities. International Journal of Special Education, 27(2), 189-206.

Buxton, C., Lee, O., \& Santau, A. (2008). Promoting science among English language learners: Professional development for today's culturally and linguistically diverse classrooms. Journal of Science Teacher Education, 195(5), 495-511. https://doi.org/10.1007/s10972-008-9103-x

Chichekian, T., Savard, A., \& Shore, B. M. (2011). The languages of inquiry: An EnglishFrench lexicon of inquiry terminology in education. LEARNing Landscapes, 4(2), 93109.

Furtado, L. (2010). Kindergarten teachers' perceptions of an inquiry-based science teaching and learning professional development intervention. New Horizons in Education, 58(2), 104-120.

Ganeb, M. D., \& Morales, M. P. E. (2018). Science fluency in primary school: Student transition from Filipino to English language learning. Issues in Educational Research, 28(3), 596.

Hmelo-Silver, C. E., Duncan, R. G., \& Chinn, C. A. (2007). Scaffolding and achievement in problem-based and inquiry learning: A response to Kirschner, Sweller, and Clark (2006). Educational Psychologist, 42(2), 99-107. https://doi.org/10.1080/00461520701263368

Kazempour, M. (2009). Impact of inquiry-based professional development on core conceptions and teaching practices: A case study. Science Educator, 18(2), 56-67.

Konicek-Moran, R., \& Keeley, P. (2015). Teaching for conceptual understanding in science. Arlington: NSTA Press, National Science Teachers Association.

Maxwell, D.O., Lambeth, D.T., \& Cox, J.T. (2015). Effects of using inquiry-based learning on science achievement for fifth-grade students. Asia-Pacific Forum on Science Learning and Teaching, 16, (1),1-31.

Miller, H., McNeal, K., \& Herbert, B. (2010). Inquiry in the physical geology classroom: Supporting students' conceptual model development. Journal of Geography in Higher Education, 34(4), 595-615. https://doi.org/10.1080/03098265.2010.499562

National Assessment of Educational Progress. (2003). Pupil's Conceptual Understanding. New York: Brent Press.

Omari, D. \& Chen, L. (2016). What is conceptual understanding? Retrieved September 13, 2019 from https://www.gettingsmart.com/2016/08/what-is-conceptual-understanding/

Rogayan D. V., Jr., \& Bautista, J. R. (2019). Filipino students' preferred motivational strategies in science: A cross-sectional survey. Indonesian Research Journal in Education, 3(2), 358-372. https://doi.org/10.22437/irje.v3i2.6828

Rogayan, D.V., Jr. \& Dollete, L.F. (2019). Development and validation of physical science workbook for senior high school. Science Education International, 30(4), 284-290. https://doi.org/10.33828/sei.v30.i4.5

Rogayan, D.V., Jr. (2019). Biology Learning Station Strategy (BLISS): Its effects on science achievement and attitude towards biology. International Journal on Social and Education Sciences, 1(2), 78-89.

Ruiz-Gallardo, J. R., \& Reavey, D. (2019). Learning science concepts by teaching peers in a cooperative environment: A longitudinal study of preservice teachers. Journal of the Learning Sciences, 28(1), 73-107. https://doi.org/10.1080/10508406.2018.1506988

Sokol, A., Oget, D., Sonntag, M., \& Khomenko, N. (2008). The development of inventive thinking: Skills in the upper secondary language classroom. Thinking Skills \& Creativity, 3(1), 34 - 46. https://doi.org/10.1016/j.tsc.2008.03.001 
Tabiolo, J.L. \& Rogayan, D.V., Jr. (2019). Enhancing students' science achievement through Jigsaw II strategy. Journal of Science Learning, 3(1), 29-35. https://doi.org/10.17509/jsl.v3i1.17680

Thompson, T. (2017). Teaching creativity through inquiry science. Gifted Child Today, 40(1), 29-42. https://doi.org/10.1177/1076217516675863

Varma, T., Volkmann, M., \& Hanuscin, D. (2009). Preservice elementary teachers' perceptions of their understanding of inquiry and inquiry-based science pedagogy: Influence of an elementary science education methods course and a science field experience. Journal of Elementary Science Education, 21(4), 1-22. https://doi.org/10.1007/BF03182354

Watters, J., \& Ginns, I. (2000). Developing motivation to teach elementary science: Effect of collaborative and authentic learning practices in preservice education. Journal of Science Teacher Education, 11(4), 301-321. https://doi.org/10.1023/A:1009429131064 